\title{
HISTÓRIA, LITERATURA E ENSINO DE HISTÓRIA: A ESCRAVIDÃO EM MARIA FIRMINA DOS REIS
}

\section{HISTORY, LITERATURE AND THE TEACHING OF HISTORY: THE SLAVERY IN MARIA FIRMINA DOS REIS}

\author{
Cleidiane Lemes de Oliveira \\ Pontifícia Universidade Católica de Minas Gerais - PUC MINAS \\ Martha Rebelatto \\ Instituto Federal de Minas Gerais - IFMG - Campus Betim
}

\begin{abstract}
RESUMO:
As obras e a trajetória de Maria Firmina dos Reis, autora negra maranhense nascida em 1822, ganharam destaque que vem se acentuando desde 1975 em eventos de literatura, publicações e no meio acadêmico. Neste artigo, interessa-nos discutir sobre os usos da literatura, especificamente o romance Úrsula, de Maria Firmina dos Reis, nas aulas de História para pensar sobre a temática da escravidão. O debate busca refletir sobre como o uso da literatura nas aulas de História pode contribuir com o processo de construção de alunos capazes de se apropriar do saber como ferramenta para interpretar o mundo e construir significados na contemporaneidade para os temas estudados. Para isso, analisaremos como a literatura, enquanto fonte para a história, dialoga com a sociedade na qual é produzida, apropriando-se e interferindo no seu tempo histórico, bem como, no caso específico da autora analisada, as condições da contemporaneidade para a releitura de Maria Firmina dos Reis. Pretendemos estabelecer alguns caminhos para trabalhar com a literatura em sala de aula, discutindo problemáticas próprias da História. Por fim, buscamos também problematizar e levar para a sala de aula o fazer do professorpesquisador e do historiador, com o objetivo de abordar como é construído o saber histórico.
\end{abstract}

Palavras-chave: literatura, escravidão, século XIX, ensino de História.

\section{ABSTRACT:}

The works and trajectory of Maria Firmina dos Reis, black female author from Maranhão born in 1822, got prominence that has been accentuated since 1975 in literature events, publications and in the academic environment. In this article, we are interested in discussing the uses of literature, specifically Maria Firmina dos Reis' novel Úrsula, in history classes to think about the slavery theme. The debate seeks to reflect on how the use of literature in history classes can contribute to the process of building 
students capable of appropriating the knowledge as tools to interpret the world and create contemporary meanings for the studied theme. To this, we'll analyze how literature, as the source for history, dialogue with the society in which it was produced, appropriating and interfering in its historic time, as well as, in the specific case of the author analyzed, contemporary conditions for the rereading of Maria Firmina dos Reis. We intend to define some ways to work with literature in the classroom, discussing the own problems of history as a discipline. Finally, we also seek to problematize and bring to the classroom the role of the teacher-researcher and the historian, in order to address how the historical knowledge is built.

Keywords: literature, slavery, 19th century, History teaching. 


\section{INTRODUÇÃO: LITERATURA COMO FONTE HISTÓRICA E O USO EM} SALA DE AULA

O uso da literatura como instrumento didático em aulas de História não é uma novidade, estando presente nos livros didáticos de forma fragmentada, junto a outros tipos de documentos históricos, sejam eles administrativos, cartas, músicas, cartazes de filmes, entre outros. Usualmente, ao final de cada capítulo do material didático, existe uma lista de sugestões de material para os alunos ampliarem ou aprofundarem os estudos, incluindo filmes, livros de ficção e não ficção e sites. Alguns livros exploram os possíveis usos desse material na parcela que é destinada ao professor.

O uso da literatura em sala de aula, bem como de outras fontes de linguagem artística, está inserido em um movimento de ampliação do que é considerado fonte histórica. A partir dos Annales, novos sujeitos, temáticas e relações com outras disciplinas são inseridos nas preocupações dos historiadores. Posteriormente, a Nova História e a História Cultural ampliam a relação com as linguagens artísticas, dando ainda mais folego às pesquisas que têm nos textos literários a base para pensar e entender as relações sociais no passado e no presente.

A partir dos anos 1980, as pesquisas em ensino de História se tornam mais diversificadas, perpassando pelo papel do livro didático, por diferentes linguagens como cinema, a história em quadrinhos, literatura, entre outras -, pelos currículos e pela formação de professores. ${ }^{1}$ As artes ganham um espaço de documento histórico e a partir de então proliferam estudos que refletem sobre os usos de linguagens artísticas em sala de aula, tanto numa perspectiva da História da Educação como do ensino da História. Dessa forma, músicas, literatura, filmes, quadros, entre outros, passam a ser mais presentes nos materiais didáticos, não apenas para legitimar o texto narrativo, mas para dialogar, questionar e até mesmo contrapor este. Assim, a inserção de fontes, didáticas e perspectivas no ensino de História está conectada aos contextos (historiográficos, políticos, sociais, culturais, tecnológicos, etc.) de formação e atuação

\footnotetext{
${ }^{1}$ Para panorama mais aprofundado sobre as pesquisas no ensino de História, ver: COSTA, Aryana Lima; OLIVEIRA, Margarida Maria Dias. O ensino de história como objeto de pesquisa no Brasil: no aniversário de 50 anos de uma área de pesquisa, notícias do que virá. Seculum - Revista de História. João Pessoa, n. 16, p.147-155, jan/jun.2007. ZAMBONI, Ernesta. Panorama das pesquisas no ensino de História. Seculum - Revista de História. João Pessoa, Departamento de história da Universidade Federal da Paraíba, n. 6/7, jan-dez. 200/2001. p.106.
} 
dos professores que elaboram e/ou utilizam materiais didáticos e que estão em sala de aula.

A despeito dessa familiaridade do uso da literatura como fonte histórica e mesmo como ferramenta didática importante, as práticas pedagógicas muitas vezes concebem o uso da literatura como uma "ilustração" do tempo histórico em que foi produzida ou mesmo do tempo que é descrito na narrativa. As práticas ficam restritas às informações do livro didático, e não à leitura da obra na íntegra. Não é o foco deste trabalho identificar os motivos da leitura apenas parcial das obras, mas podemos arriscar, com grande assertividade, que as dificuldades para a leitura integral de obras passam pela necessidade, de capacitação/formação continuada do professor, bibliotecas com poucas obras/exemplares ou desatualizadas, falta de recursos para os alunos adquirirem as obras, entre outros.

Tal qual nos fala Miriam Hermeto, ao analisar o uso das canções populares no ensino de História, quando a abordagem das linguagens e obras artísticas leva em consideração sua relação com a sociedade, o processo de ensino-aprendizagem pode ser muito mais amplo e significativo (HERMETO, 2012, p. 14). Questionar sobre o contexto e processos de produção e circulação da obra (ou do gênero), sobre seu público, sobre o contexto socioeconômico, político, cultural em que o autor estava inserido, sobre o gênero literário e como todos esses fatores influenciam tanto a obra em si como a sua aceitação possibilita ampliar os horizontes de leitura histórica de mundo dos alunos.

Assim, é necessário colocar a literatura como o objeto que nos permite conhecer mais sobre a sociedade, e não meramente como um ilustrador dela. Nesse sentido, a literatura aqui é concebida como uma interferência concreta do autor, por meio da escrita, no seu tempo histórico. Essa tarefa requer do docente um planejamento para a execução das práticas pedagógicas a serem realizadas com o documento em questão, além de um certo "desapego" das aulas conteudistas, privilegiando a reflexão histórica. Isso porque, tal qual a pesquisa histórica propriamente dita, a sala de aula também tem o propósito de responder problemas e, mais do que isso, de desenvolver competências relacionadas ao entendimento metodológico da construção do conhecimento (CAINELLI; TOMAZINI, 2017). 


\section{O ROMANCE ÚRSULA COMO DOCUMENTO HISTÓRICO}

Quando trabalhamos com literatura é possível problematizar as questões próprias da disciplina, tais como: Por que a literatura ser considerada um documento histórico? Por que a história construída com base em documentos literários é importante? Como a obra possibilita um entendimento mais complexo de outra temporalidade? E ainda questões específicas da obra escolhida: O que a história narrada no texto literário traz de contribuição para a compreensão da trajetória dos homens e mulheres no Brasil Império (no caso do romance Úrsula)? Para tanto, é preciso conceber a sequência de ensino na perspectiva didático-pedagógica e histórica, trazendo para sala de aula a reflexão sobre os processos de construção da própria aula, apresentar a metodologia, qual o argumento dela, como o professor organizou, selecionou e expôs as informações e documentos (SEFFNER, 2000). Desse modo, introduzimos no contexto das aulas de forma fluida a percepção de como o conhecimento é construído metodologicamente.

Problematizar a relevância do uso da literatura, e neste caso específico do romance Úrsula, possibilita discutir a própria historicidade das construções históricas, os motivos por que ela é escrita de uma ou outra forma, as influências do tempo presente do historiador, as técnicas e tecnologias de cada tempo, a disponibilidade de acervos e por que documentos (como a literatura) que em determinados momentos não eram considerados relevantes são valorizados em outros. É possível ainda explicitar as escolhas do professor, deixando o aluno ciente e consciente de que a sala de aula não é mera réplica do conhecimento produzido em universidades ou mesmo do conteúdo pré-selecionado pelos autores do livro didático. O professor elabora tanto a forma de abordar os temas - especialmente se pensarmos que o número de aulas é bastante reduzido para algumas matérias, portanto recortes são fundamentais - como os materiais que usará, tais como livro didático, documento histórico, filme, música, entre outros. É fundamental que os alunos entendam a necessidade dessas escolhas, pois assim, além da consciência de que o ensino - tal qual a produção do conhecimento acadêmico - não é imparcial, também não é, e nem pode ser, aleatório e desprovido de objetivos claros, metodologia e compromisso com o diálogo com outras pesquisas sobre a temática apresentada. 
Assim, é possível construir a percepção de que o conhecimento não é neutro, o que não significa a ausência de metodologias ou a manipulação de informações, nem todos esses pontos precisam ser trabalhados em uma única aula. Mas, se a reflexão sobre como se dá a investigação histórica e o porquê é importante fazê-la estiver presente na rotina do professor, esses temas serão trabalhados ao longo do ano de forma constante e mais efetiva do que, por exemplo, apenas em uma aula introdutória. Cada vez que nos utilizamos de um novo tipo de documento, problema ou mesmo metodologia, temos a oportunidade de discutir com os alunos sobre o fazer e ensinar História.

Quando utilizamos um romance como fonte, é fundamental reconhecer que a obra escolhida não responderá qualquer pergunta sobre o passado. Portanto, faz-se importante definir, primeiramente, quais questionamentos o livro de Firmina dos Reis pode nos ajudar a responder. Nesse sentido, o livro Úrsula permite pensar sobre as características de duas temporalidades do livro, primeiro o tempo da produção (século XIX), depois o tempo da redescoberta e da divulgação ampla (décadas finais do XX e XXI). A possibilidade do debate sobre essas duas temporalidades pode ser apresentada como motivadora da escolha do livro, uma vez que a obra teve pouco destaque no momento da sua publicação e uma vigorosa circulação na atualidade. Esse destaque oportuniza discussões sobre diversas transformações sociais: o lugar da mulher na sociedade, como a visão sobre a escravidão e sobre o próprio passado se alteraram, mudanças e permanências sobre o mercado editorial, entre outras.

Introduzir algumas questões do livro escolhido, sem comprometer a narrativa contada, ajuda a criar uma expectativa positiva que motiva o interesse pela leitura. No caso de Úrsula isso é fundamental, pois é um romance difícil tanto pela linguagem do século XIX como pela escrita característica do romantismo, com a qual os alunos estão pouco habituados. Buscar parcerias com professores de literatura ou língua portuguesa também é uma ótima estratégia para tornar o trabalho interdisciplinar.

Úrsula possibilita aguçar a percepção do aluno para os processos ligados à ampliação da ocupação de espaços públicos pelas mulheres, pelo fortalecimento de políticas inclusivas e, especialmente, pela ampliação dos debates na esfera pública sobre temas ligados a questões étnico-raciais como fatores fundamentais para o sucesso da obra no presente. Maria Helena Machado destaca, na introdução da edição 
da Penguin e Companhia das Letras, que o ressurgimento de Firmina no século XXI alcança inclusive a música popular, estando presente na letra de rap dos artistas Herz e Verck, do grupo de rap Gíria Vermelha, intitulada "Herói de preto é preto" que fala "sou mina que é de fibra, herói de preto é preto tipo Cosme e Firmina" (MACHADO, 2018, p. 7 e 15). A presença de Cosme e Firmina na letra da música já pode ser vista como uma evidência das mudanças sociais e culturais que permitem que as trajetórias desses indivíduos cheguem ao público mais amplo, mas também tem um papel divulgador dessas narrativas interferindo na realidade para que cada vez mais pessoas tenham interesse em saber suas histórias.

Pensando o espaço da sala de aula, é possível, inclusive, partir da escuta da música e de questionamentos sobre o conhecimento dos alunos acerca dos indivíduos mencionados para pensar os usos que se faz do passado e sobre o silenciamento em relação a autores ou indivíduos negros na história do Brasil. Como estamos pensando o ensino, não podemos deixar de mencionar os questionamentos e as demandas pelas narrativas que os alunos trazem para a escola. A presença de autoras negras consagradas como Maria Carolina de Jesus e Conceição Evaristo, os questionamentos sobre o "papel" da mulher na sociedade despertam o interesse de acadêmicos e do público em geral por conhecer mais narrativas, trajetórias e obras de autoras negras. Nesse sentido, as transformações sociais também pedem novas formas de abordar a temática da escravidão, do trabalho e da desigualdade étnico-social em sala de aula, buscando narrativas que mostrem a complexidade das relações e experiências de pessoas negras livres e escravizadas.

O movimento negro ganha destaque na construção de narrativas outras sobre os sujeitos negros no Brasil. Segundo Nilma Lino Gomes (2017), o movimento negro é educador da sociedade brasileira. Ele tem papel importante na produção de saberes emancipatórios e na sistematização de conhecimentos relacionados à questão racial. Além disso, ainda segundo Nilma Lino Gomes (2012), a ampliação ao direito à educação básica e a maior democratização do acesso ao ensino superior, especialmente por meio da política de cotas, possibilitou que sujeitos antes invisibilizados ou desconsiderados como sujeitos de conhecimento pudessem colocar demandas políticas, "tornando explícitos os paradigmas no qual algumas culturas e formas de 
conhecer o mundo se tornaram dominantes em detrimento de outras por meio de formas explícitas e simbólicas de força e violência” (GOMES, 2012, p. 101-102).

As questões colocadas por Nilma Lino Gomes são muito significativas para pensarmos, inclusive, no espaço da sala de aula, quanto do nosso desconhecimento sobre Maria Firmina, ausente em livros didáticos e desconhecida por tanto tempo, está ligado à invisibilização de sujeitos e de conhecimentos ao longo da nossa história. É possível ainda pensar o oposto, isto é, o quanto o olhar mais atento ao passado pode descortinar pessoas como Maria Firmina, mas também os processos que a silenciaram, para que possamos refletir sobre os marcadores de desigualdade presentes ainda em nossa contemporaneidade.

Nesse sentido, a História enquanto disciplina que se preocupa com as temporalidades pode contribuir muito para a construção da percepção de mudanças e permanências. Como nos alerta Peter Lee, entre os alunos prevalece a perspectiva "conformista" em relação ao presente, como algo normalizado, que faz parte da realidade, da experiência vivida, e o passado como algo muito distante, tendo dificuldades para estabelecer os elos com a atualidade (LEE, 2016. p. 137). Essa perspectiva, ainda segundo o autor, dificulta que os alunos vislumbrem possibilidades de mudanças em suas vidas futuras, pois naturalizam as relações sociais do presente. Essa percepção é inclusive antagônica à própria História, que trabalha com mudanças bastante significativas ao longo do tempo. Portanto, entendemos que oportunizar os questionamentos sobre as condições do presente que colaboram para que a obra Úrsula e sua autora tenham ganhado destaque na literatura nacional ajuda a construir perspectivas temporais, compreendendo que determinados períodos potencializam ou minimizam determinados pontos de vista, comportamentos e mesmo a circulação de obras. Além de trazer elementos para pensar sobre as ações dos indivíduos que permitiram o questionamento de aspectos considerados "normais", naturalizados no período da escrita da obra - como a escravidão, que era legitimada e garantida como direito de propriedade pelo Estado brasileiro.

É possível, por meio da exploração desses tensionamentos sociais, aprofundar conceitos como de permanências e rupturas (SEFFNER, 2019, p. 168-172) que foram engrossando um caldo social que demandava transformações, permitindo que o aluno identifique os embates nos processos de mudanças e continuidades ao longo do tempo. 
A narrativa apresentada na obra - que questiona a escravidão, a condição inferior atribuída ao negro escravizado na sociedade de meados do século XIX e, mais do que isso, traz a voz de personagens escravizados narrando as experiências vivenciadas e suas interpretações sobre o futuro - pode ser explorada como uma interferência por parte da autora para questionar aspectos do status quo escravista. Essas abordagens em sala de aula forçam o aluno a identificar o passado como plural e a história como uma construção, e não como algo óbvio. Assim, reflexões sobre o tempo da escrita e sobre como mulheres e negros foram marginalizados ao longo da história possibilitam questionar sobre as dificuldades para a escrita e publicação da obra no seu tempo, mas também sobre a colaboração da mesma para questionar e intervir no seu tempo, fortalecendo a perspectiva dos sujeitos históricos e do entendimento do passado como plural.

Quanto aos caminhos e relacionamentos sociais que oportunizaram o romance Úrsula ser publicado em meados do século XIX por uma mulher, negra, maranhense, oriunda de classe social com baixas condições econômicas, ainda restam muitas lacunas. É importante ressaltar que o próprio Machado de Assis, com todo o reconhecimento da obra e notoriedade que terá ainda em vida, não se posiciona claramente sobre a cor da sua pele e suas origens mestiças. Tal fato certamente colabora para o processo de embranquecimento social que o autor irá passar durante o século XIX e de que certo modo é naturalizado até os dias de hoje. Muito embora hoje Machado seja lido como um crítico da escravidão e a análise do seu estilo de escrita o torne fonte inclusive para a compreensão da sociedade escravista do XIX, ainda é possível achar imagens do autor como branco até mesmo em livros didáticos. Na carta abaixo escrita por Joaquim Nabuco após a morte de Machado, em resposta a comentários sobre a sua cor de pele, é possível especular sobre as dificuldades que Firmina encontrou e os motivos pelo esquecimento da sua obra.

(Carta de Joaquim Nabuco após a morte de Machado de Assis) "Mulato, foi de fato um grego da melhor época". Eu não o teria chamado mulato e penso que nada lhe doeria mais do que essa síntese. Rogo-lhe que tire isso, quando reduzir o artigo a páginas permanentes. A palavra não é literária e é pejorativa. O Machado para mim era branco, e creio que por tal se tomava: quando houvesse sangue estranho, isto em nada afetava a sua perfeita caracterização caucásica. Eu pelo menos só vi nele o grego. (NABUCO apud MASSA, cit., p. 
46. MASSA, Jean-Michel. A juventude de Machado de Assis. Tradução de M. A. de M. Matos. Rio de Janeiro: Civilização Brasileira, 1971)

Fica evidente na fala de Nabuco que o termo mulato era considerado pejorativo, portanto, não poderia ser colocado como um adjetivo para Machado, que tinha uma obra e atitudes para ele muito mais compatíveis com a de brancos. Firmina também não era branca, era de origem pobre e mulher, fatores que, além da obra em si, contribuem para o seu esquecimento. Outra autora feminina que terá ainda mais destaque em sua época e depois cai no esquecimento histórico, sendo recentemente republicada, é Julia Lopes de Almeida (1862-1934). Esta, ao contrário de Maria Firmina, era branca e fez parte de grupos de intelectuais, o que não foi suficiente para a sua obra de excelente qualidade entrar numa história da literatura ou fazer parte dos livros que compõem o rol de leitura da educação básica. Tal ponto reforça os marcadores de desigualdade que Maria Firmina acumulava e o impacto desses para o reconhecimento ou mesmo conhecimento da autora e de sua obra.

A conquista da publicação certamente teve um empenho pessoal grande, do contrário, não seria possível em uma sociedade em que a mulher era considerada como pertencendo ao espaço privado (o que inclusive aparece no seu romance de forma marcante), ainda mais sendo pobre. Maria Firmina conseguiu romper barreiras e marcadores sociais de desigualdade tendo se tornado professora e autora. Como nos fala Machado, e tantos outros autores que trabalham com a obra e a vida dela, colocar na capa do romance apenas "uma Maranhense” e de se desculpar pela "ousadia” logo nas primeiras páginas era uma postura necessária para angariar a aceitação da obra (MACHADO, 2018, p.17-18).

Pensando na perspectiva do ensino, é possível trabalhar com os alunos resenhas de obras de autores/as distintos/as publicados/as em jornais. Isso porque o livro de Maria Firmina terá resenhas publicadas em jornais de época. Essa atividade proporciona experenciar uma das principais formas de divulgação do conhecimento, opinião e formação da época, que eram os jornais. Mesmo que o jornal em si não seja o objeto da análise, a atividade apresenta a dimensão investigativa de como ou onde buscar indícios para pensar o século XIX, especialmente no caso da divulgação e circulação de impressos. A comparação de diferentes resenhas pensada 
metodologicamente (mesmo jornal e/ou período e/ou local e/ou corrente literária) possibilita trabalhar a capacidade de identificar se há diferença no tratamento por ser um trabalho de um homem ou de uma mulher, se entre homens ou mulheres existe diferença de acordo com a classe social, o número de resenhas e a frequência das publicações. As apreciações sobre o livro Úrsula são positivas, mas pouco elogiosas. É possível explorar os discursos que cada periódico seguia e a forma como usualmente são naturalizados na escrita determinados termos que tratam uma obra feminina como secundária, trabalhando uma leitura mais crítica, comparativa, que considere perspectivas diferentes. Pelo desconhecimento preliminar dos alunos em relação aos jornais do século XIX ou mesmo de resenhas e formas de publicação literária no período, a atividade permite ainda que a posição dos alunos em relação a um tema seja formulada após uma investigação, mesmo que breve. Não podemos pensar que, se trabalhamos em sala sempre com a informação já construída, os alunos vão entender os processos necessários para chegar àquele ponto e refletir individualmente sobre as pesquisas e embates para a construção dos saberes. Discutir, apresentar metodologias e teorias possíveis é imprescindível para formar jovens que consigam identificar a diferença entre uma opinião e um estudo. No caso da obra Úrsula, podemos identificar que mesmo que a autora tenha rompido várias barreiras ao publicar a obra, mostrando que é possível "desfazer as teias da opressão e do silenciamento gerados pela escravidão e pela exclusão" (MACHADO, 2018, p. 14-15), não podemos esquecer que a pouca aceitação da obra quando da sua publicação e o esquecimento da autora por um longo período evidenciam as forças contrárias às suas ideias presentes naquela sociedade.

\section{A ESCRITA DE MARIA FIRMINA: HISTÓRIA, LITERATURA E ESCRAVIDÃO}

Buscar entender as razões pelas quais a obra de Maria Firmina ficou tanto tempo desaparecida, não tendo ganhado destaque algum na história da literatura nacional por um longo período, pressupõe analisar as opiniões da autora sobre a escravidão, possíveis de ser identificadas nas falas dos escravizados no romance Úrsula, em contos e também pelo que sabemos da vida da autora. Como nos fala Chalhoub (2018, p. 299), as críticas à escravidão estão amplamente presentes na literatura brasileira durante o 
segundo reinado. Alguns autores são mais conhecidos, como é o caso, por exemplo, de Machado de Assis, Castro Alves e Luiz Gama. Assim, Firmina não destoa por apresentar uma exclusividade na argumentação contrário à escravidão, e sim por ser mulher, negra e especialmente por colocar na narrativa a voz direta dos escravizados. O romance Úrsula nos permite pensar uma forma de apresentar a temática da escravidão em um diálogo entre a história e a literatura e entre literatura e escravidão, destacando a consciência histórica do escravizado, apresentada especialmente por meio dos personagens Túlio e Susana.

Construir aulas que levem os alunos a refletir sobre o longo passado escravista do Brasil e suas implicações na formação da sociedade brasileira ainda é um desafio, especialmente pela tendência de focar nas análises que mostram a violência ou a desumanização nas ações destinadas aos escravizados, sobretudo, com o objetivo de aproximar os problemas sociais contemporâneos relacionados ao racismo e à desigualdade social ao passado escravista. Essa perspectiva, contudo, pode ser uma armadilha, pois o aluno acaba recebendo a informação de um passado pouco plural e limitando as experiências e atuações da população escravizada à própria escravidão. Não que está não seja uma dimensão relevante, pelo contrário, é impossível que ela não esteja presente na análise. O perigo está em não dar acesso a experiências desses indivíduos escravizados, privando os alunos da percepção das disputas, rupturas e permanências em torno da escravidão.

A historiografia brasileira sobre escravidão, a partir da década de 1980, inspirada sobretudo em estudos de E. P. Thompson, passou por uma grande revisão, buscando ressaltar os escravizados enquanto agentes sociais de transformação da escravidão, ultrapassando a análise dos aspectos jurídicos ou legislativos da questão (LARA, 1995, p. 46). É nesse momento que surgem quantitativamente e qualitativamente mais trabalhos referentes às mulheres, pessoas pobres e marginalizados da historiografia (loucos, presos, etc.), sendo que também os escravizados passam a ganhar um destaque nas pesquisas, como também metodologias, fontes e temáticas se diversificam. Entender as relações familiares, perspectivas de gênero, formas de negociações entre personagens com poder distintos, histórias regionais e locais proliferam nas pesquisas, eventos acadêmicos e programas de pós-graduação (CHALHOUB; SILVA, 2009). 
Dessa perspectiva, as atitudes de escravizados, libertos e livres passam a ser analisadas como iniciativas que respondiam também a projetos próprios e/ou coletivos e que interferiram na reconfiguração de relações sociais. Os materiais didáticos acompanharam as mudanças e problematizam o passado escravista, bem como a permanência de práticas, instituições e estruturas racistas em nossa sociedade contemporânea. Essas análises nos auxiliam a compreender as dinâmicas sociais da época, as relações entre as diversas camadas da sociedade - suas lutas, acomodações, permanências e rupturas. $^{2}$

Entendemos que a narrativa apresentada por Maria Firmina ajuda a apresentar uma visão diferente, pois a autora atribui consciência histórica a suas personagens, mostrando-as como agentes que lembram e interpretam sua história:

\begin{abstract}
- Sim, para que estas lágrimas?!...Dizes bem! Elas são inúteis, meu Deus; mas é um tributo de saudade, que não posso deixar de render a tudo quanto me foi caro! Liberdade! Liberdade... Ah! Eu a gozei na minha mocidade! - continuou Susana com amargura.

- Túlio, meu filho, a gozou mais ampla, não houve mulher alguma mais ditosa do que eu. Tranquila no seio da felicidade, via despontar o sol rutilante e ardente do meu país, e louca de prazer a essa hora matinal, em que tudo aí respira amor, eu corria as descarnadas e arenosas praias, e aí com minhas jovens companheiras, brincando alegres, com o sorriso nos lábios, a paz no coração, divagávamos em busca das mil conchinhas, que bordavam as brancas areias daquelas vastas praias. Ah! Meu filho! Mais tarde deram-me em matrimônio a um homem, que amei como a luz dos meus olhos, e como penhor dessa união veio uma filha querida, em quem me revia, em quem tinha depositado todo o amor da minha alma: - uma filha, que era a minha vida, as minhas ambições, a minha suprema ventura, veio a selar a nossa tão santa união. E esse país de minhas afeições, e esse esposo querido, e essa filha tão extremamente amada, ah Túlio! Tudo me obrigaram os bárbaros a deixar! Oh! Tudo, tudo até a própria liberdade. (REIS, 2018, p. 120-121)
\end{abstract}

O trecho destacado é uma fala da escravizada Susana, raptada no continente africano, escravizada, transportada para o Brasil e vendida a comerciantes locais. É possível, pela narrativa, identificar a violência presente na trajetória da personagem, mas a história vai além, trazendo as relações que ela estabelece de afetuosidade,

\footnotetext{
${ }^{2}$ VER: CHALHOUB, S. Visões da liberdade: uma história das últimas décadas da escravidão na Corte. São Paulo: Companhia das Letras, 1990. SLENES, R. W. A. Na senzala, uma flor: esperanças e recordações na formação da família escrava: Brasil Sudeste, século XIX. Rio de Janeiro: Nova Fronteira, 1999. LARA, S. H. Campos da violência: escravos e senhores na capitania do Rio de Janeiro, 1750-1808. Rio de Janeiro: Paz e Terra, 1988. REIS, J. J.; SILVA, E. Negociação e conflito: a resistência negra no Brasil escravista. São Paulo: Companhia das Letras, 1989.
} 
solidariedade, entre outras. Ao trabalhar em sala de aula a fruição desse texto literário, é necessário pensar formas de construir com os alunos o entendimento de que os indivíduos escravizados também possuíam consciência histórica que os orientava de forma particular na agência da sua vida. A consciência histórica, como definida por Rüsen, seria “a soma das operações mentais com as quais os homens interpretam sua experiência da evolução temporal de seu mundo e de si mesmos de forma tal que possam orientar, intencionalmente, sua vida prática no tempo" (RÜSEN, 2001, p. 57).

Essa consciência da própria história é mais presente nas personagens escravizados do que nos próprios protagonistas, Úrsula e Tancredo, que, na maior parte do tempo, parecem muito mais estarem sendo conduzidos pelo acaso e sucumbirem a ações trágicas ou mesmo se despedaçarem emocional e fisicamente diante de situações adversar. Já Túlio e Susana, pelo contrário, apesar do sofrimento profundo relacionado à experiência de ser escravizado - no caso de Susana - ou da separação de familiares, da presença da morte, da violência física e psicológica, parecem conseguir traçar formas de sobreviver a essas condições. Analisando o pouco que sabemos da vida de Firmina, especialmente pela publicação do seu diário por José Nascimento Morais Filho, é possível identificar a atuação prática da escritora em ações contrárias à escravidão, por exemplo, adotando algumas crianças filhas de mães escravizadas (MORAIS FILHO, 1975, p. 18-19) ou mesmo na sua negação de ir receber o diploma de professora em um "palanquim" conduzido por escravizados, pertencentes a sua tia Henriqueta, sob a justificativa de que "negro não é animal pra se ir montando nele” (MORAIS FILHO, 1975, p. 13). Isso ainda sem mencionar o conto "A escrava”, também de sua autoria, que, embora não seja objeto deste trabalho, pode ser destacado como um texto claramente crítico da escravidão.

Desse modo, a consciência da sua condição, a capacidade de análise de seu passado e das perspectivas de futuro atribuída às personagens Túlio e Susana nos permite ler como uma forma encontrada por Firmina para se colocar e para despertar em seu leitor as mazelas da escravidão. Essa perspectiva apresentada por Firmina, de trazer como personagens negros escravizados, nascidos no Brasil e em África, narrando inclusive sobre a experiência de ser capturado e transportado para o Brasil, tem uma importância abismal se pensarmos no contexto em que a obra é publicada (1859/60), pois nesse momento não são poucos os discursos que objetivam exatamente o 
contrário, isto é, deslegitimar a natureza humana desses indivíduos escravizados especialmente, embora não exclusivamente, por meio de um discurso que colocava o econômico no centro da análise, criando a perspectiva que justificava, legitimava e criava a ideia de que o Brasil não sobreviveria sem a escravidão. Tal discurso pode ser observado diretamente em jornais, como também indiretamente, na manutenção, por exemplo, dos anúncios de fuga e quilombos na grande maioria dos periódicos.

A presença de um anúncio de fuga colabora para criar a perspectiva de legitimidade e normalidade da escravidão. Ao contrário, o ato de se negar a ser carregada por escravizados marca uma posição de qual comportamento não deveria ser visto como normal ou como necessário para colocá-la em um lugar socialmente destacado dentro daquela sociedade. A fala do Marquês de Barbacena, no ano de 1837 no Senado, mostra como era construída a narrativa que priorizava os interesses da elite em detrimento da população escravizada como algo natural e que estaria defendendo os interesses de todo o país. Essa fala é duas décadas anteriores à publicação do livro de Firmina, mas ainda assim muito válida para entendermos o papel e as disputas em torno da narrativa que aborda o tema da escravidão. Além disso, a análise do discurso e do texto literário nos permite pensar duas esferas sociais distintas, uma do campo do sensível e outra do econômico.

Não havendo braços livres como não há, para substituir os escravos, a consequência necessária será diminuir anualmente e com extraordinária rapidez o produto de nossas fazendas, porque as moléstias, velhice e mortalidade, dão cabo do maior exército, não havendo recrutamento. Duro é sermos condenados a pobreza voluntária; mas, pois, que o Governo assim o quer, dê as providências que entender para que os escravos não desembarquem no Brasil, e contente-se com isso. Pretender que os lavradores não comprem escravos quando lhes levarem à casa, quando mesmo muitas vezes não há meios de conhecer se são ou não de contrabando, é exigir mais do que pode fazer a espécie humana. (...) sustentei afouto que, havendo circunstâncias em que a razão e a política aconselham o esquecimento do crime, nunca foram elas mais imperiosas do que a respeito daquele de que falo. Não são brasileiros turbulentos ou revolucionários, que com as armas na mão quiseram derrubar o Governo e a constituição, aos quais, algumas vezes se tem concedido anistia; são proprietários tranquilos, chefes de famílias respeitáveis, homens cheios de indústria e virtude, que promovem a fortuna particular e pública com seu trabalho, os quais, por dobrados títulos merecem completo esquecimento sobre as infrações que cometeram. (CHALHOUB, 2012, p. 73-75) 
O trecho acima foi retirado do discurso proferido pelo então Marquês de Barbacena, que pretendia justificar as razões por que senhores e comerciantes estavam descumprindo a lei de 1831, que impunha o fim do tráfico atlântico de africanos escravizados, e propunha a revogação da referida legislação. O discurso é um documento fantástico para entender as construções narrativas elaboradas em torno da escravidão e como estas são fundamentais para a visão naturalizada dos escravizados como inferiores (em nenhum momento são eles que sofrem) e não só humanizando os donos de escravizados, mas tornando-os vítimas de uma situação injusta que os condenava à "pobreza voluntária” e por consequência levaria à falência de todo o país, uma vez que esses mesmos proprietários promoviam não apenas a sua fortuna, mas também a fortuna pública. Quando apresentados em sala dois discursos com objetivos tão distintos como estes, é importante apresentar o público a que estava destinado e os interesses envolvidos nas narrativas. Dessa forma, é possível analisar a escrita, o objetivo do texto, os argumentos e a forma como eles são apresentados para tentar convencer ou sensibilizar o público.

Em Úrsula apresenta-se um caminho oposto ao proposto por Barbacena. Não só os escravizados, como as próprias personagens principais, Úrsula e Tancredo, são vítimas dos autoritarismos que a sociedade escravista e patriarcal produzia. As duas personagens masculinas, comendador Paulo B, tio de Úrsula, e o pai de Tancredo são vistos como corrompidos pelo poder, como capazes das maiores atrocidades porque não estão acostumados a serem contrariados. A tragédia do assassinato de Tancredo e a loucura e morte de Úrsula, embora centrais no texto, compõem um cenário autoritário com a presença de outras mortes, como a de Susana, a da mãe de Túlio e a de outras personagens escravizadas e não nomeadas, bem como a da mãe de Tancredo.

Enquanto Barbacena coloca os grandes proprietários como "vítimas" do governo ao tentar acabar com o tráfico de Atlântico de escravizados, Firmina coloca esses proprietários como moralmente corrompidos, que não têm limites para o exercício da violência e do autoritarismo, o excesso de poder os corrompe e os torna incapazes de serem contrariados. Tancredo é a exceção, que pelo imenso amor que a mãe lhe dedica consegue identificar as necessidades, anseios e a dor nas pessoas que estariam abaixo dele social e hierarquicamente naquela sociedade. A narrativa elaborada por Firmina no romance Úrsula, e em outras de suas publicações, ajuda em 
alguma medida a descredenciar uma certa construção de "normalidade" da escravidão como algo válido e mesmo necessário. Há de se identificar uma intencionalidade no discurso que coloca os escravizadores nos papéis de "vilões" e os escravizados como "vítimas", mas com consciência e valores considerados nobres para o período, como a lealdade e a gratidão.

Aqui cabe salientar que não é nossa intenção praticar uma inversão de papéis, colocando todos escravizados em uma mesma situação e imbuídos dos mesmos anseios e todos os proprietários do outro lado - nem essa é a intensão de Firmina. A autora traz debates entre personagens escravizadas Susana x Túlio e Túlio x Antero, que nos dão pistas para abordar a diversidade e a pluralidade das experiências desses indivíduos. Ela também nos indica uma diversidade entre o autoritarismo dos homens de elite proprietária ao colocar amor e devoção nas características que definem a personalidade de Tancredo. Também nos permite refletir, mais uma vez, sobre o tempo de Firmina. Adjetivar seus personagens escravizados com bondade, dedicação, gratidão, respeito, lealdade pode ser visto pela perspectiva interna do romance como externa da sociedade. Se esses adjetivos são imputados para despertar a sensibilidade do leitor em relação à população escravizada, ou seja, para desenvolver a simpatia do leitor em relação a determinados personagens, imputam-se qualidades admiradas entre os próprios leitores nesses atores. Isso nos aponta para quais caraterísticas de comportamento social eram consideradas positivas, pelo menos nos romances do período.

Estamos aqui nos atendo a questões relacionadas à escravidão, mas certamente o romance nos permite realizar essa análise em outros aspectos da sociedade. O caso da mulher é emblemático, pelo fato de a personagem principal ser uma mulher e a mãe de Tancredo também ter um papel orbital na questão feminina do romance. Aqui cabe destacar inclusive a diferença entre o feminino branco e o feminino negro. Enquanto Úrsula e a mãe de Tancredo são descritas quase como santas pela subordinação e dedicação à vontade dos homens, pela fraqueza da alma causada pela doçura e pelo amor (os homens estão erados quando abusam delas, mas a devoção em si é positivada), Susana é descrita como resiliente, pela capacidade de sobreviver a dores como a separação dos filhos e do marido. Tanto a mãe de Túlio quanto Susana sucumbem pelos maus-tratos e pelos castigos, mas não pelas "dores da alma”. O que 
une estas mulheres, brancas livres e negras escravizadas, é a dominação masculina a que em maior ou menor grau elas estão subjugadas. $\mathrm{O}$ que as separa seria a força de sobreviver dessas mulheres negras escravizadas e a fragilidade das personagens brancas.

O contexto em que Firmina escreve também deve ser levado em consideração para analisar essas distinções, bem como os romances que influenciam esse gênero literário, as características desse amor romântico quase sempre impossível e que serve de cenário para a história narrada.

A narrativa do livro contribui para o entendimento e a complexidade desse passado, mas não é o passado. Assim, ao trabalhar o romance em sala de aula com os alunos, é oportuno inclusive trazer a experiência de outras mulheres livres e escravizadas, brancas e negras para contrapor a visão romantizada dessas personagens no texto.

O romance Úrsula pode ser considerado importante para entender o passado escravista, por trazer a dimensão do sensível e, com isso, contrapor o discurso econômico, fatalista em relação ao final da escravidão e que criava discursos que tentavam definir os proprietários como "senhores de bem que promovem a fortuna particular e pública com seu trabalho”, construindo uma narrativa que legitimava inclusive a escravização ilegal como algo positivo e necessário para o país. O romance de Firmina e os autores de literatura em geral que se posicionaram contrários à escravidão mostram outra face dessa narrativa, mostrando o poder desses proprietários, para além até da questão econômica, mas destacando que os "benefícios" desse poderio não só não traziam "fortuna” para a população em geral como eram construídos sobre a miséria física e psicológica de boa parte da sociedade, especialmente dos hierarquicamente inferiores na cadeia do patriarcado, isto é, mulheres, crianças e escravizados.

Assim, pensar a sala de aula como espaço de análise de discursos que possam auxiliar os alunos a entender e decifrar os interesses envolvidos na construção de determinadas narrativas e, para além disso, como essas narrativas ganham mais ou menos força em determinados espaços da sociedade, dependendo de quem as pronuncia torna os alunos capazes de ler e interpretar o presente com ferramentas utilizadas para analisar o passado. 


\section{CONSIDERAÇÕES FINAIS}

O uso da literatura como fonte histórica já é bastante consolidado, sendo linguagem escrita carregada de costumes, interpretações, personagens, cenários que podem não ter ocorrido/existido, mas são marcas históricas e culturais, representação de uma determinada realidade social, o que transforma as obras literárias também em material didático-pedagógico valioso. A literatura possibilita, no âmbito do ensino de História, nos aproximar dos contextos históricos estudados e questionar metodologias próprias da construção do saber histórico.

No caso específico do livro Úrsula, de Maria Firmina dos Reis, entendemos que um dos grandes ganhos com a leitura e análise do percurso da obra, para seu uso na disciplina História, é entender as características de duas temporalidades do livro, primeiro o tempo da produção (século XIX) e de seu esquecimento até o tempo da redescoberta e da divulgação ampla (décadas finais do XX e XXI). Pensar essas temporalidades permite que o professor trabalhe mudanças e continuidades nas estruturas tanto social e étnico-racial no Brasil, estabelecendo os principais agentes alavancadores das mudanças e as resistências para a permanência de estruturas racistas e excludentes.

Por fim, permite pensar o ensino da temática da escravidão por um enfoque mais plural, estabelecendo a importância da estrutura escravista para a manutenção de desigualdades estruturais na sociedade brasileira, mas destacando também as lutas protagonizadas pelos indivíduos negros - incluindo aí o campo da literatura como ferramenta política de atuação na sociedade - para transformar a sociedade, evidenciando indivíduos que romperam os marcadores de desigualdade e conseguiram fazer parte de círculos considerados pertencentes a indivíduos brancos e como muitas destas trajetórias foram moldadas ou silenciada ao longo do século XX.

\section{Referências}

ALMEIDA, Júlia Lopes de. A falência. São Paulo: Via Leitura, 2018. 
CAINELLI, Marlene Rosa; TOMAZINI, Elizabete Cristina de Souza. A aula-oficina como campo metodológico para a formação de professores em história: um estudo sobre o Pibid/História/ UEL. História \& Ensino, Londrina, v. 23, n. 2, p. 11-33, jul./dez. 2017

CHALHOUB, Sidney. A força da escravidão: ilegalidade e costume no Brasil Oitocentista. São Paulo: Companhia das Letras, 2012.

CHALHOUB, Sidney. Literatura e escravidão. In: SCHWARCZ, Lilian M; GOMES, Flávio (Org.). Dicionário da escravidão e liberdade. São Paulo: Companhia das Letras, 2018. p. $298-304$.

CHALHOUB, Sidney; SILVA, Fernando Teixeira da. Sujeitos no imaginário acadêmico: escravos e trabalhadores na historiografia brasileira desde os anos 1980. Caderno AEL, v. 14, n. 26, 2009. Disponível em: https://www.revistas.usp.br/revhistoria/article/view/18593/20656. Acesso em: dez. 2019.

GOMES, Nilma Lino. O movimento negro educador: saberes construídos nas lutas por emancipação. Petrópolis: Vozes, 2017.

. Relações étnico-raciais, educação e descolonização dos currículos. Currículo sem Fronteiras, v. 12, n. 1, p. 98-109, jan./abr. 2012.

HERMETO, Mirian. Canções populares e ensino de história: palavras, sons e tantos sentidos. Belo Horizonte: Autêntica, 2012.

HOSHINO, SILVA. Um estudo sobre a representação de mãe Susana no livro Úrsula de Maria Firmina dos Reis em 1859. 2010. Anais do XX Encontro Regional de História: História e Liberdade. ANPUH/SP - UNESP-Franca. Disponível em: https://www.anpuhsp.org.br/sp/downloads/CD\%20XX\%20Encontro/PDF/Pain\%E gis/ALINE\%20EIKO\%2OHOSHINO.pdf

LARA, Silvia Hunold. Blowin'in the Wind: E. P. Thompson e a experiência negra no Brasil. Projeto História, São Paulo. 12 out, 1995.

LEE, Peter. Literacia histórica e história transformativa. Educ. Rev., Curitiba, n. 6o, p. 107-146, jun. 2016.

MACHADO, Maria Helena Pereira Toledo. Maria Firmina dos Reis: invisibilidade e presença de uma romancista negra no Brasil do século XIX ao XXI. In: REIS, Maria Firmina dos. Úrsula. São Paulo: Penguin Classics Companhia das Letras, 2018.

MASSA, Jean-Michel. A juventude de Machado de Assis. Tradução de M. A. de M. Matos. Rio de Janeiro: Civilização Brasileira, 1971

MORAIS FILHO, José Nascimento. Maria Firmina: fragmentos de uma vida. São Luís: Imprensa do Governo do Maranhão, 1975. 
REIS, Maria Firmina dos. Úrsula. São Paulo: Penguin Classics Companhia das Letras, 2018.

SEFFNER Fernando. Mudanças e permanências. In: FERREIRA, Marieta de Moraes; OLIVEIRA, Margarida Maria Dias de (Coord.). Dicionário de Ensino de História. Rio de Janeiro: FGV, 2019. p. 168-172.

SEFFNER, Fernando. Leitura e escrita na história. In: NEVES, Iara Conceição Bitencourt et al. (Org.). Ler e escrever, compromissos de todas as áreas. Porto Alegre. Editora da UFRGS, 2001. p. 107-120.

TELLES, Norma. Rebeldes, escritoras, abolicionistas. Rev. Hist. [online]. n. 120, p. 73$83,1989$.

WILLIAMS, Raymond. A produção social da escrita. São Paulo: Editora Unesp, 2014.

Sobre as autoras

\section{Cleidiane Oliveira:}

Possui graduação em História pela Universidade Federal de Santa Catarina (2003), mestrado em História pela Universidade Federal de Santa Catarina (2006) e doutorado em História pela Universidade Federal de Minas Gerais (2012). Tem experiência na área de História, atuando principalmente nos seguintes temas: escravidão, século XIX, história social do trabalho, ensino de história. Atua como professora de História do IFMG - Campus Betim (2015).

\section{Martha Rebelatto:}

Estudante do Programa de Pós-graduação em Educação (doutorado) da Pontifícia Universidade Católica de Minas Gerais. Cursou mestrado em Educação e licenciatura em História pela mesma instituição. Foi professora substituta do Instituto Federal de Minas Gerais (IFMG) campus Betim. É integrante do Grupo de Estudos e Pesquisas sobre a Profissão Docente - GEPPDOC. Desenvolve pequisas sobre decolonialidade, ensino de história e formação de professores. 